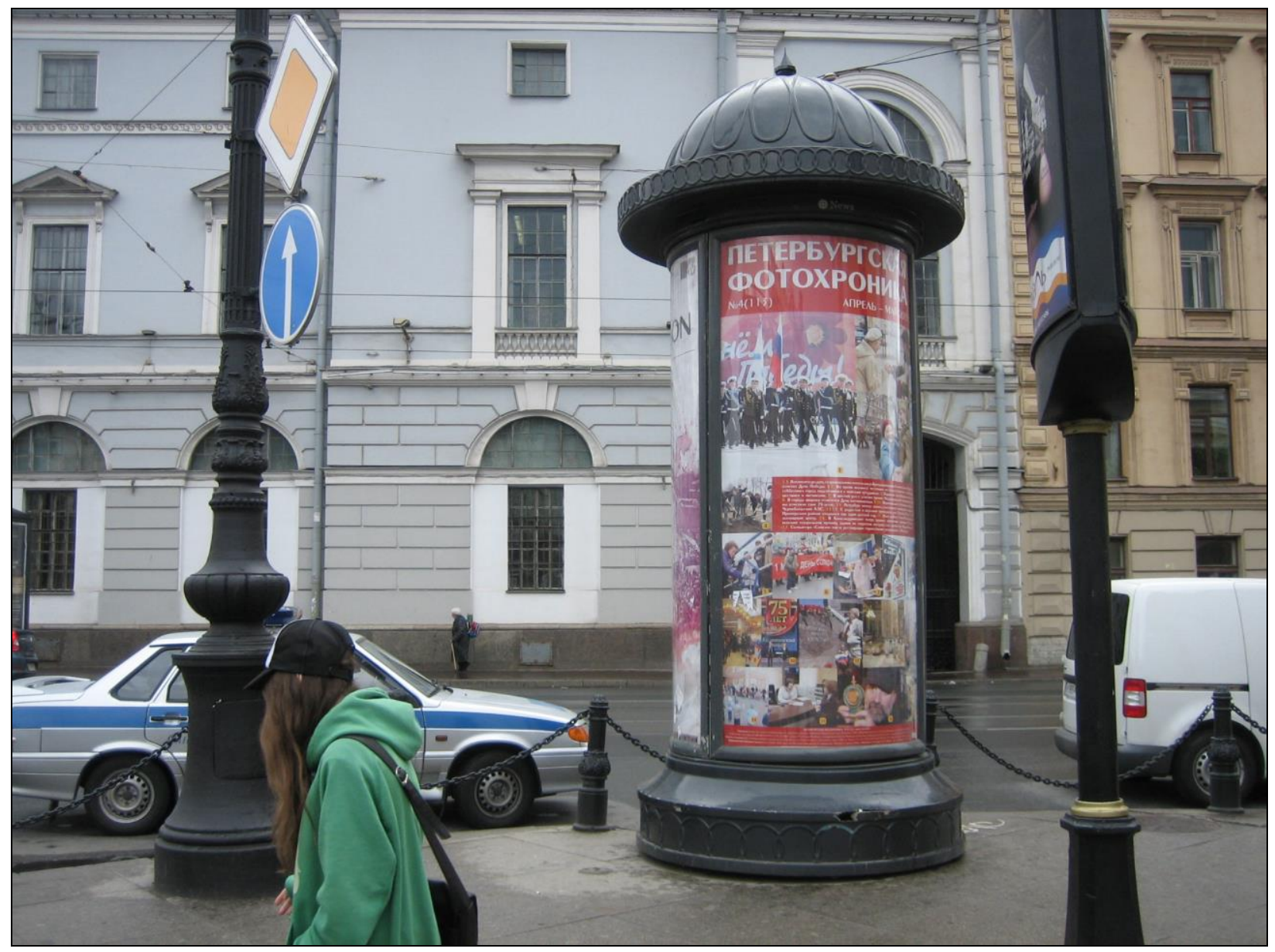

Photo credit: Elena Siemens

\title{
Shabby Chic Afternoon
}

Elena Siemens and Christine Wiesenthal University of Alberta, Canada

This project captures, in words and images, a single afternoon in St Petersburg, Russia and Toronto, Canada. Notwithstanding their many differences (age, architecture, style, sensibility), both St Petersburg and Toronto belong to Yury Lotman's category of "eccentric" cities. Any city, Lotman writes, is a place "where different national, social and stylistic codes and texts confront each other"; as such, it is inevitably a "place of hybridization" (194). But "eccentric" cities, those situated "at the edge" - "on the sea shore, at the mouth of a river" - take this hybridization to the maximum (192). Lotman cites the example of St Petersburg, whose "spatial antithesis" (the "clear demarcation" of its space between "stage" and "behind the scenes") has been interpreted in literature as a "mutual relationship of non-existence" (197). Each of the two St Petersburg's "scenes," Lotman points out, has produced its own stories associated with particular "streets, districts, their own space" (199). Christine Wiesenthal's poem "Jane Street, January" depicts Toronto's "behind the scenes" space: "shabby corner diners"; "a plaster-cracked apartment above a pet store." The poem's story about a 
TranscUlturAl, vol. ? (2016), PP-PP.

http://ejournals.library.ualberta.ca/index.php/TC

bittersweet visit with friends is set against a "slushy grey January day." In St Petersburg, the weather was a mix of sun and clouds. My father wanted to visit Alexander Pushkin's house-museum, an attractive 19th-century mansion located on one of St Petersburg's many canals. Later that afternoon, we went to a small café near our hotel - a less affluent neighbourhood more reminiscent of Dostoevsky's Crime and Punishment than Pushkin's Eugene Onegin. I said I felt at home in this city. "As you should," my father smiled in reply, "you were conceived here."

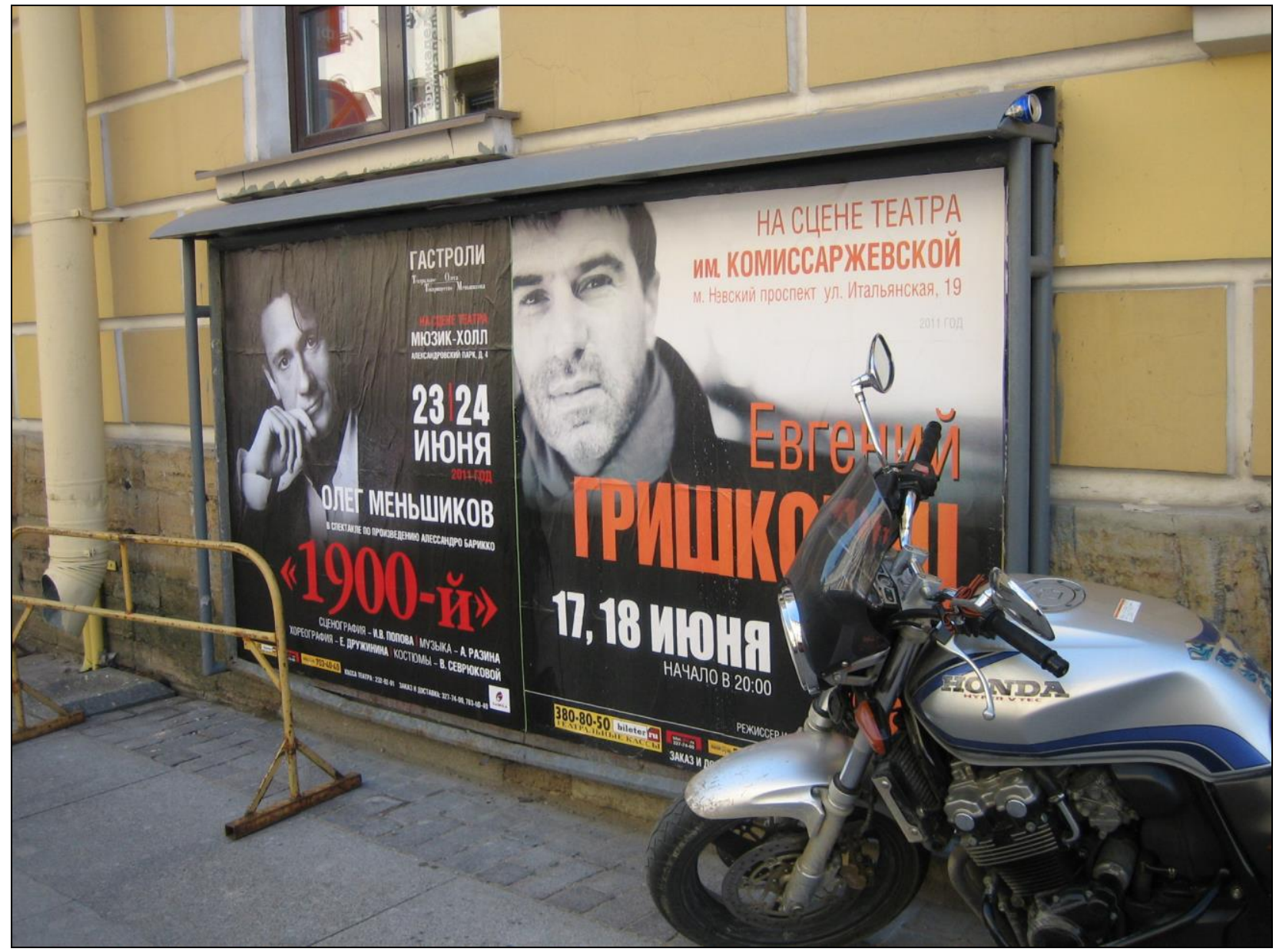

Photo credit: Elena Siemens 
Transc UlturAl, vol. ? (2016), PP-PP.

http://ejournals.library.ualberta.ca/index.php/TC

\section{Jane Street, January}

A slushy grey January day

on Jane Street \&

I hold the daffodils

stiffly in front of me:

splattered egg yokes or

perhaps artificial suns

You hold the wine

To cut through the gloomy

rush hour streets we dash past

shabby corner diners \&

over muddy gutters, soggy

snow flakes falling thick as

rag paper pulp scrap

from the sky

These are flowers for your old

Toronto friends, two jobless people

In a plaster-cracked apartment

above a pet store

their Beef Wellington is rare,

the moody cockatiel is too

$\&$ they are new parents

What else would they need

this slushy grey day

on Jane Street

but a cluster of flowers, a lovely

little lemon clutch of lies. 
TranscUlturAl, vol. ? (2016), PP-PP.

http://ejournals.library.ualberta.ca/index.php/TC

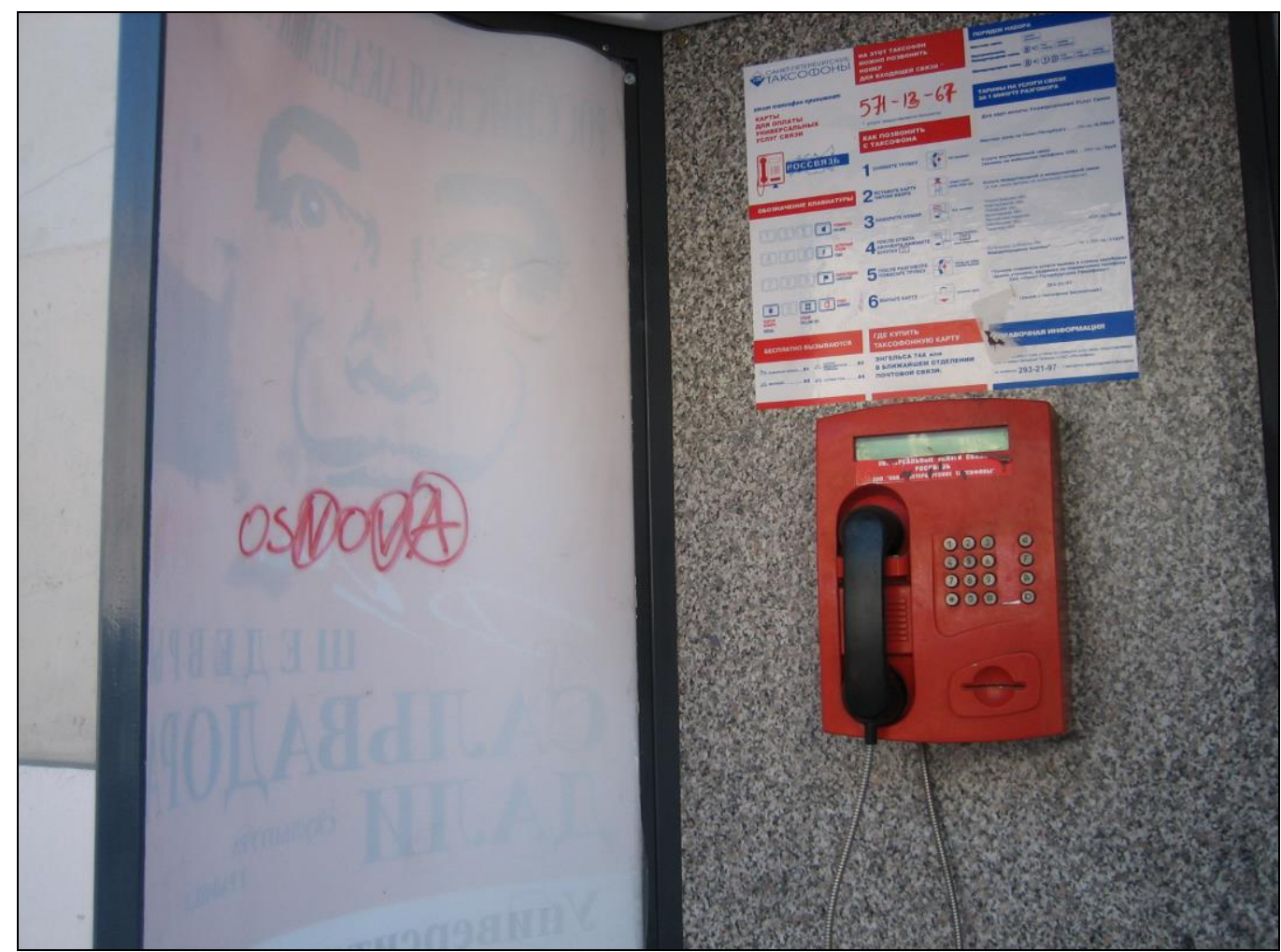

Photo credit: Elena Siemens

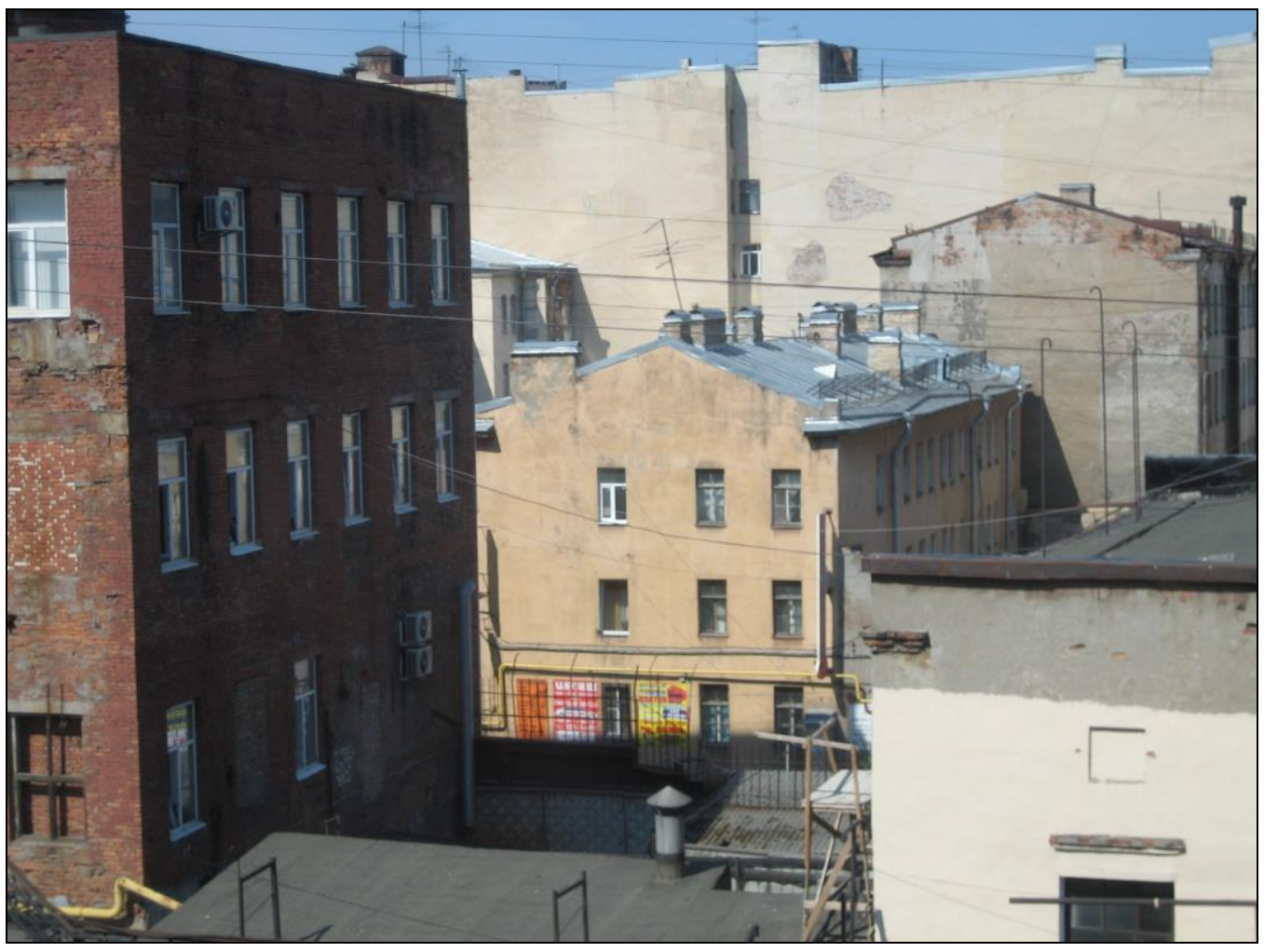

Photo credit: Elena Siemens 
Transc UlturAl, vol. ? (2016), PP-PP.

http://ejournals.library.ualberta.ca/index.php/TC

\section{REFERENCES}

Lotman, Yury. Universe of the Mind: A Semiotic Theory of Culture. Bloomington: Indiana UP, 2009. Print.

Wiesenthal, Christine. Instruments of Surrender. Ottawa: BuschekBooks, 2001. Print. 